\title{
San Camilo, 1936: cuando la censura volvió a ser un problema para Camilo José Cela*
}

\author{
San Camilo, 1936: quando a censura foi novamente um problema para Camilo José Cela \\ San Camilo, 1936: when censorship was again a problem for Camilo José Cela
}

\author{
Olivia Rodríguez-González
}

Universidade da Coruña - A Coruña - Espanha

\begin{abstract}
Resumen: En este artículo se informa de los problemas que Camilo José Cela tuvo con la censura franquista cuando se editó en 1969 su novela San Camilo, 1936, que tiene como tema el comienzo de la guerra civil española en Madrid. El cese en 1969 de su amigo Manuel Fraga Iribarne como ministro de Franco significó el fin de su posición privilegiada como escritor en la España de los años 60. La reacción contra Cela por parte de los elementos más retrógrados del Régimen, enemigos del ex-ministro, no se hizo esperar. Finalmente, la novela circuló con recortes que se sumaron a los que el autor realizó por la autocensura habitual en la época.
\end{abstract}

Palabras clave: Camilo José Cela; San Camilo 1936; novela de la guerra civil española

Resumo: Este traballo relata os problemas que Camilo José Cela teve com a censura franquista quando publicou em 1969 seu romance San Camilo, 1936, cujo tema é o início da Guerra Civil Espanhola, em Madri. O fato de Manuel Fraga Iribarne, amigo de Cela, deixar de ser ministro de Franco significou o fim de sua posição privilegiada como escritor na Espanha dos anos 60. A reação contra Cela pelos elementos mais retrógrados do regime, inimigos do ex-ministro, foi rápida. Finalmente, o romance circulou com cortes que foram adicionados aos que o autor realizou por causa da auto-censura de costume na época.

Palavras-chave: Camilo José Cela; San Camilo, 1936; Literatura da Guerra Civil Española

Abstract: This paper reports on the problems that Camilo Jose Cela had with Franco's censorship when he published in 1969 his novel San Camilo, 1936, whose plot concerns the beginning of the Spanish Civil War in Madrid. The cessation in 1969 of his friend Manuel Fraga Iribarne as a Minister in Franco's regime meant the end of Cela's privileged position as a writer in the Spain of the 60 's. The reaction was swift against Cela by the most retrograde elements of the regime and enemies of the ex-minister. Finally, the novel circulated with cuts added to those the author already performed following the usual self-censorship at the time

Keywords: Camilo José Cela; San Camilo, 1936; Literature of the Spanish Civil War

\section{Introito}

Cela publica en 1969 Visperas, festividad y octava de San Camilo del año 1936 en Madrid, su contribución novelística al trigésimo aniversario del fin de la guerra de España (1936-1939) o, de acuerdo con el lenguaje franquista, a los 30 años de paz. Desde los inicios de su carrera novelística ha estado presente el tema de la guerra, como no podía ser menos en un narrador que practica una estética expresionista y lleva a cabo un retrato de la España coetánea, a la manera de Goya, Valle Inclán o Gutiérrez Solana. En 1961, Cela afirma que tanto $L a$ familia de Pascual Duarte (1942) como La Colmena (1951) podían considerarse novelas de la guerra civil, aunque "tangenciales a la catástrofe", y que aún iba a tardar en escribir su auténtica novela de la guerra:

\footnotetext{
* Este trabajo se ha llevado a cabo dentro del Proyecto de Investigación financiado por el Ministerio de Economía y Competividad y FEDER (FFI 201235872), en el que participa la autora, profesora titular de Teoría de la Literatura y Literatura Comparada de la Facultad de Filoloxía, Universidade da Coruña, Campus da Zapateira, 15071-A Coruña, España (olivia@udc.es).
} 
La novela, sin adjetivos, de la guerra entiendo que no debo escribirla por ahora ya que pienso que es demasiado amargo demostrar al mundo que fue una contienda entre hijos de putas, salvo honestas excepciones por parte de quienes, a un lado y a otro, clamaban sin éxito ni suerte por poner punto a la matanza. Tiempo al tiempo. (CELA, 2009a, p. 799)

Pocos años después se enfrenta con una novela exclusivamente dedicada al tema de la guerra, con escenario madrileño y un corto lapso temporal que fue analizado por Darío Villanueva (1994, p. 222). Las vísperas y octava de la celebración de la fiesta solemne de San Camilo de Lelis, muerto el 14 de julio de 1614, abarcan desde los preliminares del asesinato de José del Castillo Sáenz de Tejada, conocido como Teniente Castillo, el 12 de julio de 1936 (FERNÁNDEZ, 2005, p. 76-77) hasta unos días después del golpe de estado del 18 de julio.

Ante su imagen proyectada en el espejo, el personaje narrador se desdobla en un monólogo continuo a través del tú que lo envuelve como receptor-narratario del discurso. El tiempo concentrado hasta el estallido violento de la guerra arrastra a los personajes como si fueran empujados hacia el sumidero de la Historia. Porque estamos ante una novela histórica, caracterización genérica que el autor subraya mediante la técnica de reconstrucción de la época con citas de recortes periodísticos. Con este recurso, recurrente por otro lado en su literatura, Cela sustituye la profundización en el fondo histórico por la ambientación fragmentada en una especie de collage de noticias y anuncios. También ayuda a perfilar la perspectiva histórica el carácter autobiográfico del relato. Un Camilo José Cela de veinte años asoma en la creación del personaje narrador. El título señala como centro temporal de los sucesos los días en torno al 14 de julio de 1936, fecha de la onomástica del escritor que entonces tenía un futuro halagüeño como poeta, tal como le auguraban en las tertulias madrileñas que frecuentaba. Nunca olvidará la de la casa de María Zambrano en la plaza del Conde de Barajas y será fiel a los que en ella le dieron la alternativa literaria: desde la filósofa del exilio a Pedro Salinas, pasando por Rafael Alberti, María Teresa León, Emilio Prados, etc. (cf. CELA, 2009a).

\section{Colaboración del ministro Manuel Fraga Iribarne en la novela}

Camilo José Cela redacta San Camilo, 1936 con ayuda de su gran amigo Manuel Fraga Iribarne, que tiene al escritor como mano derecha en asuntos relacionados con la cultura, mientras ejerce como ministro de Información y Turismo desde 1 de julio de 1962 hasta el 29 de octubre de 1969. Prueba de este apoyo inusitado es que la revista que Cela dirigía en Palma de Mallorca,
Papeles de Son Armadans (1956-1979), tuvo el privilegio de ser censurada esos años en la Dirección General de Prensa del del MIT, a cargo de Manuel Jiménez Quílez, puenteando Cela al encargado de tal menester, Francisco Soriano Frade, Delegado de Información en Mallorca con el que había tenido múltiples disensiones (CELA, 1962).

En agosto de 1967 Cela está trabajando ya en la novela de la guerra civil, pues el día 28 de ese mes se lo comunica a Manuel Fraga por carta: "Estoy metido de lleno en una novela", y le pide para documentarse sobre la época el ABC, El Debate, El Sol, El Socialista y El Liberal, "preferentemente" (CELA, 1967). Eso da la medida de qué tipo de ayuda le va a prestar el ministro haciéndole enviar a su casa-taller de Palma de Mallorca ejemplares, suponemos que de la Hemeroteca Nacional o, cuando menos, de los archivos ministeriales. Que a partir de entonces recibe los periódicos de la época en que se ambienta la novela se confirma por la carta de dos años después en que Cela le agradece a Fraga las colecciones del ABC y El Sol (CELA, 1969a).

Tras duros años de movilizaciones obreras y estudiantiles y la repulsa internacional frente a los excesos represivos de Franco, se inicia 1969 con un estado de excepción decretado por las huelgas en las universidades de Barcelona y Madrid. A finales de enero, el estudiante Enrique Ruano es asesinado por la policía y el Régimen disfraza el hecho con un increíble suicidio que la prensa del Movimiento, orquestada por el Ministerio de Información y Turismo, se encarga de propalar. El 22 de febrero se reúnen en Collioure (Francia) intelectuales del interior y el exilio para homenajear a Antonio Machado ante su tumba en el trigésimo aniversario de su muerte. Franco nombra sucesor, en una Jefatura del Estado que desempeña vitaliciamente, a Juan Carlos de Borbón el 22 de julio y le hace jurar un día después en las Cortes fidelidad al Régimen.

Alfaguara, sello editorial creado en 1965 por los hermanos Jorge y Camilo José Cela Trulock, se dispone a editar en otoño la nueva novela del reputado escritor y académico, San Camilo, 1936.

\section{Presentación a la censura de San Camilo, 1936}

La editorial Alfaguara presenta la galeradas de la novela, es decir, las páginas ya maquetadas, pero sin encuadernar, a Consulta voluntaria en el MIT, tal como preveía la Ley de Prensa e Imprenta del 9 de abril de 1966. La Consulta obligatoria de la Ley anterior, promulgada en plena guerra civil, quedaba eliminada por los artículos 3 y 4 o de la conocida popularmente como "Ley Fraga" (DUEÑAS, 1969), pues había sido este ministro el encargado de elaborar una nueva norma legal en principio 
más permisiva, aunque se demostraría en la práctica que lo que cambiaba era sólo los mecanismos de control, pero no su intensidad (RODRÍGUEZ, 2008, p. 550-553). La consulta obligatoria podía, por otro lado, exigirse en caso de que se decretase el estado de excepción, tal como ocurrió entre el 24 de enero y el 21 de marzo de 1969. Otras imposiciones de la nueva ley eran - en lo referido a los libros, pues las publicaciones periódicas tenían tratamiento aparte - el depósito de ejemplares de las publicaciones antes de su circulación y la posibilidad de que, una vez en la calle, la obra fuese secuestrada, lo que traía consigo duras sanciones tanto a los autores como a los editores.

Alfaguara, editorial con sede en el no 35 de la calle Orense de Madrid, tiene al frente a Jorge Cela Trulock. Es él quien firma la instancia al Director General de Información, en la que se anuncia para San Camilo, 1936, dentro de la colección "Alfaguara Literaria", una tirada de 10.000 ejemplares de 443 páginas (formato $14,5 \times 21,5$ ) a un precio de 200 pts. Jorge Cela rellena, por lo que se ve, un formulario antiguo que debía de guardar en sus oficinas, pues la instancia lleva el sello del Servicio de Orientación Bibliográfica de la Dirección General de Información, que en 1969 pasa a llamarse de otro modo igualmente eufemístico: Servicio de Ordenación Editorial y a depender de la Dirección de Cultura Popular y Espectáculos (ABELLÁN, 1980, p. 109-110)ํ․․

El expediente de este Departamento se inicia el 30 de septiembre con el número 9556-69, haciéndose constar que la obra es destinada al "lector 12". Una mano anota en la parte superior: "Urgente", detalle que indica que el proceso no va a seguir un curso normal, sino privilegiado $^{2}$.

El primer censor leyó la novela en solo 9 días e informó muy negativamente sobre ella el 9 de octubre de 1969. Su firma se lee sin dificultad, cosa rara en los expedientes de censura, rubricados por lo general con trazos ilegibles. Se trata de Rafael Casas de La Vega (1926-2010), en aquel tiempo comandante del ejército, falangista y autor de Brunete, libro de 1967 con el que iniciaría una tarea de interpretación de la guerra civil como militar y pre-revisionista, combinada con la de biógrafo del dictador en 1995, 20 años después de su muerte. No se trata de un expediente al uso, para el que había un formulario detallado, sino de un informe en dos folios, con los epígrafes: "Argumento", "Desarrollo de los

\footnotetext{
1 Así se bautizó en enero de 1968 la que, hasta la llegada de Fraga, se había llamado "Sección de Inspección de Libros". En 1962, el nuevo ministro la denominó "Sección de Orientación Bibliográfica". Desde 1963 publicó un Boletín de Orientación Bibliográfica que continuaría hasta 1976.

2 Todas las citas que se hagan a partir de este momento de los documentos del expediente de censura, no paginados, remiten a: Expediente AGA, 1969-1970.

3 Páginas: 21, 22, 39, 64, 73, 110, 121, 144, 271, 322, 351 y 431.
}

más importantes hechos narrados", "Parecer personal" y un apéndice con los "principales reparos" agrupados por materias y con indicación del número de páginas en las que ha hecho anotaciones a mano. De estas páginas con tachaduras, el archivo del AGA solo conserva doce ${ }^{3}$.

Este primer lector aconseja no autorizar el libro, puesto que San Camilo, 1936 contiene, a su juicio, abundantes muestras de ataque al Régimen. $\mathrm{Al}$ resumir el argumento, informa de que los hechos se desarrollan durante los días anteriores y posteriores al 18 de julio. El protagonista, "joven de la burguesía madrileña, cobarde, tísico, completamente pervertido" lleva a cabo, acompañado de otros tres jóvenes, el asesinato del Teniente Castillo. El resto de los personajes pertenece a la burguesía y el ambiente dominante, descrito con todo lujo de detalles, es prostibulario: advierte de la técnica distorsionada de una novela que también considera "estudio exhaustivo, de las casas de lenocinio madrileños de la época".

Asegura este militar que se ataca "con discreción, a veces, pero siempre con evidencia y eficacia, al Ejército, a la Patria, y muy especialmente, a la Religión". Es evidente que con sus comentarios trata de perjudicar a Camilo José Cela. Así, al indicar que trata el asesinato de "D. José Calvo Sotelo" con desapasionamiento, añade entre paréntesis que "hay una curiosa semejanza de puntos de vista entre los relatos oficiales comunistas con este hecho y el de Camilo José Cela, que fue Alférez Provisional de Artillería". Y por si eso fuera poco, señala que en la novela no se relata la persecución roja en Madrid. Todo lo contrario: se reproducen letras de canciones anarquistas y hasta un discurso de Dolores ibárruri. Termina dando su "parecer personal": supera en contenido pornográfico a obras anteriores de Cela, con respecto a las cuales ofrece una novedad:
su ataque sistemático a todo ideal religioso o político del actual Estado español. Hace de una manera evidente causa común con los enemigos del Régimen y expone conceptos históricos y sociales desacreditados, pero muy en boga entre ciertos círculos revolucionarios de hoy día. Este libro en manos de muchos jóvenes no sólo daría lugar a una deformación moral monstruosa, sino también contribuiría a deformar los criterios sobre nuestra guerra en favor del bando que la perdió. (palabras subrayadas a mano en el original del expediente)

Finalmente, señala el censor el número de páginas en las que ha marcado con lápiz "reparos" que él mismo organiza por "materias": "Pornografía" en 55 páginas, "Perversión sexual" en 13, "Crueldad" en 6, "Cinismo blasfemo" en 17, "Ataques a la Iglesia" en 14, "Idem al Estado" en 16, "Idem al Ejército" en 17, "Derrotismo" en 8 y "Ataque a las buenas costumbres" en 7 . 
Como se ve, este experto en la guerra civil española, más como militar falangista que como historiador objetivo, se ensaña con el autor. Su informe hace saltar las alarmas de los amigos de Cela, el citado Fraga y el cuñado de este, Carlos Robles Piquer, que ocupa el cargo en el MIT de Director General de Cultura Popular y Espectáculos ${ }^{4}$. Es Robles Piquer el primero en recibir el informe y es Fraga Iribarne quien escribe a Cela para transmitirle la mala noticia. Cela les contesta el 16 de octubre de 1969. Han pasado nada más que cinco días desde que el censor entregó su informe.

En su carta ${ }^{5}$, Fraga debió de intentar consolar al escritor, pues este se muestra agradecido en su respuesta: "Te agradezco muy de veras tu interés por mi novela, por todas mis cosas. Quizás sepas que esa leal amistad que me profesas no es unilateral". Cela le manda también a Fraga la copia de la carta que va a enviar a Robles Piquer. No es la primera vez, y nos permitimos hacer este inciso, que se evidencia en la correspondencia del trío Cela, Fraga y Robles Piquer la enorme diferencia de tono con que el escritor se dirige a cada uno de ellos. Por Fraga siente un amor y respeto inmensos por la complicidad absoluta que había entre ambos. A Robles Piquer se dirige con altanería y despecho, pero en esta ocasión se doblega en cierta medida.

En la carta intenta hacer Cela un alarde de honradez y lealtad ante los que llama amigos, después de dejar claro que le duele la noticia del informe negativo, aunque ni le sorprende ni le preocupa. Asegura no arrepentirse de haber presentado su novela a la consulta voluntaria, pero reconoce "haberse equivocado en la táctica". Suponemos que con estas palabras se está refiriendo a la decisión personal, o quizás aconsejada por los amigos que ocupan altos cargos políticos, de solicitar un informe, no a un censor ignaro, sino a una persona considerada en el seno del ejército como especialista en historia militar de la guerra civil. Al parecer, Robles le ha pedido que tome un avión a Madrid y se presente en el MIT para hablar con él, así que Cela le comunica que viajará el 24 de octubre para verse los dos al día siguiente. Cela le agradece la invitación para hablar del asunto, pero el resto de la carta es una declaración de principios:

\footnotetext{
4 Entre 1967 y 1969. Entre 1962 y 1967 había sido Director General de Información.

5 Solo disponemos de las copias de las cartas de Cela archivadas en el AGA. No se puede saber si la carta de Fraga se conserva y si se custodia en la Fundación pública del autor en Iria Flavia (A Coruña). Según nos informó en noviembre de 2015 telefónicamente Covadonga Rodríguez, directora de la Fundación Camilo José Cela, a petición de una comisión integrada por el bibliógrafo Fernando Huarte, ya fallecido, y por el catedrático de literatura de la Universidad de Barcelona, Adolfo Sotelo, el Patronato tomó la decisión en 2011 de considerar toda la correspondencia de Cela con Fraga Iribarne y Robles Piquer, entre otras personas físicas o sociales, como "archivos reservados". Las cartas citadas en este trabajo pertenecen a archivos del AGA, a excepción de algunas que la autora consultó en la Fundación Camilo José Cela en 2010, antes de la prohibición de consulta de esos fondos.
}

Entiendo que San Camilo, 1936 es una novela patriótica y sé de sobras -y nada me importa- lo que los críticos comprometidos han de decir de ella. También entiendo -y me acongoja, aunque, te repito, ni me sorprende ni me preocupa- que tus informadores, a los que cabe suponer en la orilla contraria a aquellos críticos, no alcancen a entender lo que pretendí al escribirla. (CELA, 1969a)

A San Camilo, 1936 se le destinaron dos censores más, en una segunda fase, para tratar de resolver el asunto de una manera favorable a Cela. Es posible que ambos conociesen, antes de emitir su fallo, el escrito del primer censor, pues aluden a ciertos puntos decisivos del fallo del primero, matizándolos o contrariándolos.

El segundo informe fue llevado a cabo por Saturnino Álvarez Turienzo, presbítero agustino, director de la revista La Ciudad de Dios, catedrático de Ética en la Universidad Pontificia de Salamanca y entre 1964 y 1967, prior del Monasterio de El Escorial. Ese mismo año de 1969 publicaba en la editorial Guadarrama el libro Revisionismo y diálogo. Madurez moral y signos del tiempo.

En su informe dice procurar seguir el desarrollo lógico de unas páginas donde, al estilo de "cierta novelística", todo se revuelve. Intenta el autor hacer "una pintura social de Madrid como espejo de España en las fechas indicadas. Esta pintura es neutral, pues no toma partido por republicanos ni por nacionales." Según él, el escritor superpone a un plano de contenido sexual otro en el que paradójicamente se expresa "una especie de sermón regeneracionista". El lenguaje es, a su juicio, "insultatorio y pornográfico". En cuanto al contenido obsceno, que pondría en riesgo un juicio favorable acerca de su posible publicación - duda, por otro lado, de que a otro autor que no fuera Cela se le tolerarían sus "atrevimientos" -, considera lo siguiente: "Como descargo sólo encuentro que lo que he llamado su pornografía es más verbal que real, en el sentido de que la descripción morosa de escenas insinuantes no es el fuerte del autor".

Opina que las intenciones de Cela son constructivas. Si es verdad que cita con complacencia nombres literarios "que no son del gusto oficial" y que no muestra entusiasmo con el Alzamiento, también es cierto que no presenta de forma tendenciosa a sus protagonistas. Finaliza con las palabras que constituyen su fallo:

La obra quiere ser apolítica, no es fácil de conseguir... Y, en fin, el guiso no será de fácil digestión. Creo que para el lector corriente de novelas esta de Cela no será de fácil lectura.

Creo que, tapando los oídos, yo la autorizaría. Al fin, no son los oídos lo[s] que definen el bien y el mal." (palabras subrayadas en el original del expediente) 
El tercer informe se redacta en el formulario que la censura empleaba usualmente. Con el número de expediente de la novela y la fecha de 21 de octubre, se custodia en el AGA un formulario original con una rúbrica ilegible. Lo acompaña una fotocopia literal, pero con distinto encabezamiento y las dos líneas finales cortadas, precisamente donde el original indica como resolución: "Autorizada". En esta copia se le con claridad la firma de [Antonio] Iglesias Laguna, que en el original no aparece. Fuera de esos detalles, llama la atención que esta vez se haya encargado el informe a un historiador de la literatura que ese mismo año, en la editorial Prensa Española, publicaba Treinta años de novela española (1938-1968). En este libro, y conviene tenerlo en cuenta, se ocupa de la trayectoria de Cela en términos elogiosos.

El informe empieza afirmando que se trata de la mejor novela de Cela, lo que no quiere decir que se trate de una "gran novela". Sigue diciendo que, tras las primeras cien páginas cargadas de un "erotismo delirante" seguramente debido a "un propósito comercial y epatante que no hace honor al gran escritor que es Cela", la novela toma cuerpo, se hace "dolorosa y a veces entrañable", y convierte su tremendismo en ternura en el último capítulo. Termina el censor asegurando que, desde el punto de vista político, "la novela es positiva, ya que no toma partido ni acusa a nadie".

Comenzamos dando por hecho que los tres informes no se pidieron de forma simultánea y hemos descrito su contenido en orden cronológico, pues, como dijimos, los censores los entregan los días 9, 16 y 21 de octubre, respectivamente. Insistimos ahora en que de la diferencia de fechas se infiere que el segundo y el tercero se pidieron después de la entrega del primero, de desaprobación fulminante. La costumbre era que la juzgase un solo lector, cuyo anonimato se intentaba mantener. Excepcionalmente, como fue este caso, se solicitaban informes a colaboradores externos que no eran cuellos duros del MIT. Ya hemos visto la opinión que el primero, falangista que reprocha a Cela que olvide que fue alférez de artillería, le merece la obra. En cambio, Saturnino Álvarez Turienzo, censor de gran consideración en el MIT desde hacía años, pertenecía al equipo de colaboradores de Fraga para el que trabaja en la reforma del Ateneo, asistiendo a las reuniones convocadas por el ministro en 1962 y aceptando el cargo de vocal en la directiva presidida desde febrero de 1963 por José María de Cossío. Se trataba de un censor de alto nivel y de la máxima confianza del ministro, que solicitaba su colaboración en "segundos informes de seguridad", como el que nos ocupa:

El judici d'Álvarez Turienzo, exposat de manera raonada $\mathrm{i}$ convincent, va ser particularment decisiu en segons informes de seguretat, que redactava, com la resta de lectors, sense conèixer-ne els precedents, redoblant l'arbitrarietat estratègica que al règim li acomodava fomentar. Els dirigents franquistes van avalar tots els dictàmens del pare Álvarez Turienzo, entre els quals figuren vuit autoritzacions, dues denegacions i una mutilació (SOPENA, 2013, p. 150).

También Antonio Iglesias Laguna, poeta además de historiador de la literatura, colabora en múltiples actos desde 1962 en el Ateneo. Este censor considera como una de las etapas más fructíferas de la institución la organizada esos años por el ministro, aunque no se refiera a él directamente (cf. IGLESIAS, [1968], p. 48-50).

Después de estos tres informes, el primero muy negativo y los dos últimos, elaborados como amortiguadores de la condena fulminante del primero, se autoriza la obra a finales de octubre. Hacemos constar ahora lo que omitimos al principio del relato de estos hechos: que en el margen izquierdo del folio de la instancia aparecía la nota manuscrita "Autorizado 29-10-69".

\section{Silencio administrativo}

La primera edición de San Camilo, 1936 sale a la luz exactamente el 4 de diciembre de 1969. ¿Qué ocurrió para que se demorara dos meses la edición?

En la documentación dispersa que obra en el expediente de censura aparece una ficha de cartón blanco, de las que se utilizaban para estos menesteres, en la que se menciona a un "lector 36 " que propone autorizar la obra presentada a la censura el 30 de septiembre de 1969, sin añadir comentario alguno. En otra ficha, de cartón azul, se indica que San Camilo, 36 , destinada al "lector 12" -el que figuraba al iniciarse el expediente-, es autorizada el 29 de octubre. Más abajo, se anota a mano: "silencio administrativo". Y, a renglón seguido: "3 de diciembre de 1969".

La aplicación del llamado silencio administrativo a una obra ya autorizada por la censura suponía algo más que su condena a entrar en un limbo editorial. Es preciso conocer el contexto de la política censora:
Si se elegía la opción de presentar directamente la obra a Depósito, se corría el riesgo de que la obra fuera denunciada al recién creado Tribunal de Orden Público y, lo que es peor, víctima de un "Secuestro Previo Administrativo". Una medida extrema que suponía un serio quebranto económico a la editorial afectada. Existía, no obstante, una fórmula intermedia conocida como "Silencio Administrativo", que significaba que el editor corría con todos los riesgos (ROJAS, 2006).

Para entender las razones de esta paralización que deja en suspenso la edición de la novela, es preciso conocer el contexto político de España esos días de octubre de 1969. 
Ocurrió que la coyuntura política que sostenía, como vimos muy débilmente, la autorización de la novela, desaparece bruscamente con la remodelación del gobierno llevada a cabo el 29 de octubre por el vicepresidente, almirante Luis Carrero Blanco. Varios ministros son cesados, entre ellos los tres tecnócratas directamente implicados en el escándalo de corrupción política conocido como el Caso Matesa. Una persona relacionada con el empresario estafador, Laureano López Rodó, sobreviviría sin embargo como Ministro del Plan de Desarrollo.

La empresa Maquinaria Textil del Norte de España, S.A. (MATESA) había obtenido desde 1964 alrededor de 10.000 millones de pesetas en subvenciones del Estado para exportaciones a través del Banco de Crédito Industrial de titularidad pública. Su objetivo era exportar una innovadora máquina sin lanzadera cuya patente había sido adquirida en Francia. Con tal motivo, se evadieron miles de millones de pesetas y en julio de 1969 se descubrió que la gran mayoría de las ventas eran simuladas. El empresario, Juan Vilá Reyes fue enjuiciado, condenado y finalmente indultado con motivo de la subida al trono de Juan Carlos I en 1976. Sus cómplices en el gobierno, entre los que se contaban los ministros Faustino García Moncó, de Comercio; Juan José Espinosa San Martín, de Hacienda; y su antecesor en el cargo y gobernador del Banco de España, Mariano Navarro Rubio, acabaron siendo indultados por Franco.

Entre los cesados en la remodelación también estaban los ministros de origen falangista que trataron de airear el caso para que los culpables saldaran sus deudas con el jefe del Estado: José Solís, Secretario General del Movimiento; Fernando María Castiella y Maíz, de Asuntos Exteriores; Pedro Nieto Antúnez, de Marina. Y como no podía ser menos, el ministro de Información y Turismo, Manuel Fraga Iribarne, que se puso al frente, y con la energía que lo caracterizaba, de la difusión pública del caso Matesa. Vio en ello una manera de debilitar la fuerza del Opus Dei, al que pertenecían Luis Carrero Blanco y los ministros tecnócratas citados, próximos a Laureano López Rodó. Dicha fuerza pretendía dirigir la futura sucesión de Franco copando el mayor poder posible en torno al sucesor, Juan Carlos de Borbón (FERNÁNDEZ, 2005, p. 285-286).

Fraga y Cela coincidían en ese anti-opusdeísmo, y cayeron juntos frente a López Rodó y Carrero Blanco, pues Cela perdía un tratamiento privilegiado en la cultura oficial del momento, siempre respaldado por su valedor.

La novela, pues, se autoriza el mismo día del cese. No puede tratarse de una casualidad, sino de una firma urgente para dar carpetazo al trámite. Fraga le pagaba de esta manera a Cela los servicios prestados.
Ahora bien, dos días después del cese fulminante de Fraga en el MIT, con fecha de 31 de octubre de 1969, el Director General - ¿Carlos Robles Piquer en funciones? - dirige un escrito al Jefe de la Sección de Orientación Bibliográfica, Faustino García-Sánchez Marín, para que se archive lo relativo a San Camilo en "el expediente del Sr. Cela".

Finalmente, el 29 de noviembre de 1969, Jorge Cela Trulock procede al depósito de seis ejemplares de San Camilo, 1936, después de aplicar algunos de los cortes sugeridos por el primer censor. Ha decidido, como vemos, arriesgarse, señal de que aún conserva en las oficinas del MIT buenos contactos. En la nueva instancia indica que prevé una tirada de 5.000 ejemplares para una obra de 448 páginas (añade las 5 sin paginar que no indicó en la instancia de septiembre, en las que se incluye el índice y el colofón $)^{6}$. Cuatro días después, como vimos, se levanta el "silencio administrativo".

\section{Nuevo episodio: denuncias}

Una vez editada, San Camilo, 1936 pasa a ser blanco nuevamente de la obsesión censoria. Ahora el ministro de Información y Turismo es Alfredo Sánchez Bella, miembro del Opus Dei pero con una trayectoria cercana a Cela por las actividades de ambos en el Instituto de Cultura Hispánica desde su fundación en los años 40. El 22 de diciembre de 1969 recibe una carta de quien es Ministro de Justicia desde 1965, Antonio María Oriol y Urquijo. Este le comunica que "un Jefe del Estado Mayor Central del Ejército" le ha remitido una crítica muy desfavorable de la novela de Cela. No sabe qué se puede hacer ya, pues la novela circula por las librerías, pero cree que era conveniente hacérselo saber.

Acompaña a esta carta de Oriol un informe sobre San Camilo, 1936. Sorprendentemente, se trata de un resumen, párrafo a párrafo, del redactado por el primer censor, Rafael Casas de la Vega, contra el contenido de la novela. Ahora aparece sin firma y sin sello. Eso indica que el militar no se conformó con el arreglo del entuerto en el MIT y pasados unos meses, lo denunció en el Alto Estado Mayor. El informe anónimo termina con este añadido: "Basándose en lo anterior sería viable interponer algún tipo de acción judicial, con posibilidades de su admisión, ya que el contenido del libro tiene elementos suficientes para ello".

Por las anotaciones manuscritas al margen de la carta de Oriol, sabemos que Sánchez Bella pide al nuevo

\footnotetext{
6 Unos días después de ser editada la novela, exactamente el 15 de diciembre de 1969, el editor de Alfaguara vuelve a dirigir un escrito a la Oficina de Ordenación Editorial para informar de que la obra, ya depositada el 29 de noviembre, va a tener finalmente una tirada de cien mil ejemplares, distribuidos en veinte tiradas de cinco mil.
} 
Director General de Cultura Popular y Espectáculos, Enrique Thomas de Carranza, que le informe sobre quién fue el responsable de la censura de esta novela. También le pregunta si es posible retirarla de las librerías. Como el Régimen está muy tocado internacionalmente, e incluso internamente después de la crisis de Matesa, advierte: "Calíbrense bien los pros y contras de cada acto que se decida".

El 2 de enero, Sánchez Bella informa a Oriol y Urquijo de que la novela fue autorizada el 29 de octubre. Las salidas que le ofrece son que la obra sea denunciada por un organismo o por "cualquier español". Piensa que la fórmula más acertada sería que lo hiciese, de oficio, el propio Ministerio de Justicia. Oriol y Urquijo, finalmente, escribe a Sánchez Bella el 16 de enero para comunicarle: "De acuerdo con los deseos que sobre este asunto me expones, lo he puesto en conocimiento, a los oportunos efectos, del Fiscal del Tribunal Supremo".

Finalmente, en la documentación archivada en el AGA sobre el asunto de San Camilo, 1936 y la censura, se incluye la copia de un "Informe muy confidencial. Asunto: Narración literaria. Título: San Camilo, 1936. Autor: Camilo José Cela". Por alguna de las referencias temporales que contiene, debió de elaborarse durante el mes de enero, quizás a propuesta de uno de los dos ministros citados. O más seguramente, del Gabinete de Enlace, creado por Fraga para mantener intercomunicados los ministerios en lo relativo al espionaje, vigilancia policial y propaganda del Régimen. Este informe recoge opiniones diversas, desde la de un electricista anónimo a la de profesionales liberales, algunos relacionados con la literatura. Todos aborrecen la obra después de su lectura. Algunos coinciden en su deseo de que se eche al fuego. Otros quieren que se expulse de la Real Academia de la Lengua a Cela. El tono de los comentarios es chabacano, de conversación de taberna. Anotamos los nombres de los comentaristas citados: Emilio Pérez Villanueva, abogado; Olegario Llamazares Gómez, ingeniero de Caminos y colaborador de las revistas de Obras Públicas; Emilio González de Hervás, escritor y periodista, y Antonio Gómez Cifuentes, "un hombre de la calle relacionado con los ambientes intelectuales". Finalmente, se recoge el ambiente de indignación que hay en el Ateneo, donde no se entiende la postura de Guillermo Díaz Plaja y de Antonio Valencia, crítico del ABC, por sus comentarios favorables publicados sobre esta obra de Cela. Termina el informe citando otras dos novelas sobre la guerra "que también están ensuciando el país": Off-Side, de Gonzalo Torrente Ballester; y La sombra de las banderas, de Manuel Pombo Angulo.

No hay más documentación sobre el final de esta historia en el AGA, por lo que desconocemos en qué pararon estas últimas maniobras de 1970. Pero conocemos su conclusión: la novela siguió en las librerías y Cela no fue llevado al TOP, Tribunal de Orden Público creado el 9 de mayo de 1963.

\section{Los efectos de la censura en el texto de San Camilo, 1936}

Constatamos que la novela se publicó con algunos de los cortes o correcciones realizados por el primer censor. Así se deduce del cotejo de las páginas de las galeradas marcadas con lápiz por el militar, que han sobrevivido -no todas- en el expediente del AGA, con el texto autógrafo mecanografiado -e incluso con su fuente manuscrita- y con la primera edición de la novela. No es este el lugar para un análisis completo de los cambios, pero sí el más indicado para ilustrar con algún ejemplo la repercusión que tuvo en la novela la censura.

Antes nos parece conveniente mencionar, para hacer más clara la génesis del texto de la novela a partir del material pre-editorial disponible, que hubo una censura autorial previa a la salida a la luz del texto: se trata de las correcciones que Cela hace en su manuscrito o en su transcripción mecanografiada (CELA, 2009b). Tienden a suavizar, por lo general, la dureza de un lenguaje repleto de "palabras prohibidas" en el diccionario de la RAE, por cuya incorporación luchó el autor desde que fue académico de número, y que constituían el corpus de su Diccionario secreto (1968) y una de las claves lingüísticas de su discurso literario. A modo de ejemplo, sirva este fragmento de los comienzos de San Camilo, 1936:

\footnotetext{
Manuscrito (fecha anotada en la página: 17/03/1969), p. 7: "Llamar a las cosas por su nombre, no llamar a las cosas por su nombre, cagarse en todo lo humano y lo divino, no cagarse en todo lo humano y lo divino. Acostarse con esta mujer que huele a sebo y a agua de colonia, no acostarse con esta mujer que huele a sebo y a agua de colonia (...), quitarse la vida con gas, no quitarse la vida con gas, tomar por el culo, no tomar por el culo, dar de comer al hambriento, no dar de comer al hambriento,..."

$1^{\circ}$ edición (04/12/1969), p. 14-15: "Llamar a las cosas por su nombre, no llamar a las cosas por su nombre, renegar de todo lo humano y lo divino, no renegar de todo lo humano y lo divino, acostarse con esta mujer que huele a sebo y a agua de colonia, no acostarse con esta mujer que huele a sebo y a agua de colonia (...), quitarse la vida con gas, no quitarse la vida con gas, dar de comer al hambriento, no dar de comer al hambriento,..."
}

En cuanto a la incorporación a la novela de algunas de las sugerencias hechas por Rafael Casas de La Vega, el primer y más implacable censor del texto, veremos algunos ejemplos significativos y lo acompañaremos de la 
razón aducida por el militar para señalarlos. Manejamos los manuscritos, tanto en su versión original como en su transcripción mecanografiada (CELA, 2009b), las páginas de la novela que contiene el expediente de censura del AGA y el texto de la 1ª edición:

\section{Ataques al Ejército:}

Texto mecanografiado (s.d.), p. 65: "Lo malo que sucede es que nadie ha inventado áun el Sobre Verde para la gota militar del alma, la mierda llama a la mierda, la mierda convierte en mierda todo lo que toca y este país, nadie lo olvide, es una mierda con delirio de grandeza, una mierda en la que todo el mundo quiere empezar desde el principio cada mañana."

Galeradas (30/09/1969), p. 110: "lo malo que sucede es que nadie ha inventado aún el Sobre Verde para la gota militar del alma, la mierda llama a la mierda, la mierda convierte en mierda todo lo que toca y este país, nadie lo olvide, es una mierda con delirio de grandeza, una mierda en la que todo el mundo quiere empezar desde el principio cada mañana." (El censor propone "sufre de delirio de grandeza ", en lugar de "es una mierda con delirio de grandeza").

1a edición (04/12/1969), p. 110: "lo malo que sucede es que nadie ha inventado aún el Sobre Verde para la gota militar del alma, la mierda llama a la mierda, la mierda convierte en mierda todo lo que toca y este país, nadie lo olvide, sufre de delirio de grandeza, aquí todo el mundo quiere empezar desde el principio cada mañana."

Manuscrito a máquina (s.d.), p. 72: “o el guardia H., que es obediente y bestia como deben ser los guardias, obedientes y bestias, la noche, el afán de aventura, el mesianismo, la verguenza de que se te note el miedo, la disciplina como máscara de las más confusas inclinaciones...".

Galeradas 30/09/1969, p. 121: “o el guardia H. que es obediente y bestia como deben ser los guardias, obedientes y bestias, la noche, el afán de aventura, el mesianismo, la verguenza de que se te note el miedo, la disciplina como máscara de las más confusas inclinaciones...". (E1 censor propone "ciego" y "ciegos", en lugar de "bestia" y "bestias").

1a edición (04/12/1969), p. 121: "o el guardia H. que es obediente y ciego como deben ser los guardias, obedientes y ciegos, la noche, el afán de aventura, el mesianismo, la verguenza de que se te note el miedo, la disciplina como máscara de las más confusas inclinaciones...".

\section{Ataques al Estado:}

Manuscrito (s.d.), p. 4; transcripción mecanografiada (s.d.), p. 14: “don Roque tiene un concepto gimnástico del amor y lo que le gusta es joder a saltos ¡zas, zas!, y cabalgando. Cuando termina da un estentóreo ¡viva España! y, si la cosa salió muy bien, grita a voz en cuello: ¡Gibraltar, español! Don Roque no cree en el pecado de la carne...".
Galeradas (30/09/1969), p. 21: “don Roque tiene un concepto gimnástico del amor y lo que le gusta es hacer el amor a saltos ¡zas, zas!, como en los concursos hípicos, cuando termina da un estentóreo ¡viva España! y si la cosa salió muy bien grita a voz en cuello ¡Gibraltar español!, don Roque no cree en el pecado de la carne...".

1ª edición (04/12/1969), p. 21: “don Roque tiene un concepto gimnástico del amor y lo que le gusta es hacer el amor a saltos ¡zas, zas!, como en los concursos hípicos, don Roque no cree en el pecado de la carne...”.

Texto mecanografiado (s.d.), p. 42: "Es fácil convertir a un mozo en asesino, también es fácil hacer de él un buen torturador, un buen policía, basta con que alguien más fuerte sepa sonreirle a tiempo como induciéndole a sentirse maduro (o histórico o mesiánico, es igual),...”. Galeradas (30/09/1969), p. 73: “Es fácil convertir a un mozo en asesino, también es fácil hacer de él un buen torturador, un buen policía, basta con que alguien más fuerte sepa sonreirle a tiempo como induciéndole a sentirse maduro (o histórico o mesiánico, es igual),...". (El censor propone "esbirro" en lugar de "policía").

1a edición (04/12/1969), p. 73: "Es fácil convertir a un mozo en asesino, también es fácil hacer de él un buen torturador, un buen esbirro, basta con que alguien más fuerte sepa sonreirle a tiempo como induciéndole a sentirse maduro (o histórico o mesiánico, es igual),...”.

Texto mecanografiado (s.d.), p. 219: "un miliciano canta por fandangos de Huelva con muy melodiosa voz de barítono, que viva el poder civil, mueran Goded, Franco y Mola, muera el que pretenda hundir la república española, ¡via el 14 de abril!".

Galeradas (30/09/1969), p. 351: “un miliciano canta por fandangos de Huelva con muy melodiosa voz de barítono, que viva el poder civil, mueran Goded, Franco y Mola, muera el que pretenda hundir la república española, ¡via el 14 de abril!" (El censor propone "Queipo" en lugar de "Franco").

1a edición 04/12/1969, p. 351: “un miliciano canta por fandangos de Huelva con muy melodiosa voz de barítono, que viva el poder civil, mueran Goded, Queipo y Mola, muera el que pretenda hundir la república española, ¡via el 14 de abril!”

\section{Por cinismo blasfemo:}

Texto mecanografiado (s.d.), p. 87: “Dios ni entra ni sale en lo que hacemos los hombres, nos contempla con un infinito desprecio, también con una infinita pesadumbre, es muy raro todo lo que nos imaginamos de Dios..."

Galeradas (30/09/1969), p. 144: "Dios ni entra ni sale en lo que hacemos los hombres, nos contempla con un infinito desprecio, también con una infinita pesadumbre, es muy raro todo lo que nos imaginamos de Dios..." (El censor propone añadir, después de "desprecio,": “con una infinita piedad"). 
1ª edición 04/12/1969, p. 144: “Dios ni entra ni sale en lo que hacemos los hombres, nos contempla con un infinito desprecio, con una infinita piedad, también con una infinita pesadumbre, es muy raro todo lo que nos imaginamos de Dios..."

Texto mecanografiado (s.d.), p. 201: "Dios no da fuerza a los débiles, ni siquiera a los débiles de buena voluntad, en eso es demasiado cruel y distante,..."

Galeradas (30/09/1969), p. 321-322: "Dios no da fuerza a los débiles, ni siquiera a los débiles de buena voluntad, en eso es demasiado cruel y distante,..."

1a edición (04/12/1969), p. 321-322: "Dios no da fuerza a los débiles, ni siquiera a los débiles de buena voluntad, en eso es demasiado distante,..."

(Queda sin especificar el motivo):

Texto mecanografiado (s.d.), p. 30: "Conchita no es muy decente -nadie dice que sea muy decente- pero sí es católica y respetuosa, ¡no hay que confundir!”.

Galeradas (30/09/1969), p. 64: "Conchita no es muy decente nadie dice que sea muy decente pero sí es católica y respetuosa, ¡no hay que confundir!”. (El censor propone: "religiosa" en lugar de "católica).

$1^{\text {a }}$ edición (04/12/1969), p. 64: "Conchita no es muy decente nadie dice que sea muy decente pero sí es religiosa y respetuosa, ¡no hay que confundir!”.

Si se llevara a cabo algún día la edición crítica de San Camilo, 1936, habría que incorporar, a nuestro juicio, lo que el censor cortó y respetar, por el contrario, las correcciones que el autor hizo antes de entregar la novela a Alfaguara. Puede que obedecieran a la autocensura que practicaban por hábito desgraciado los escritores de la época, cediendo a las imposiciones invisibles del régimen, pero al menos eran decisión de Cela, y no enmiendas de mano ajena y hostil.

\section{Para concluir}

Acabamos de ver cómo los demonios de la censura se revolvieron de nuevo contra Camilo José Cela. Sucedió cuando creía haber superado la fase más dura como escritor vigilado en una dictadura donde se había acomodado a duras penas en una posición ambigua y no siempre rebelde: basta recordar cómo él mismo había ejercido el oficio de censor, muy bien pagado, en los años $40^{7}$. Las turbulencias del Régimen durante el tardofranquismo hicieron que Cela volviera a vivir una pesadilla parecida a la de sus inicios con La familia de Pascual Duarte y

\footnotetext{
7 El propio Cela cuenta en su segundo libro de memorias que trabajó como censor interino, ocupando la plaza vacante de Eugenio Suárez, corresponsal de la Segunda Guerra Mundial. Se ocupaba de las publicaciones Boletín del Colegio de Huérfanos de Ferroviarios, Farmacia Nueva y El Mensajero del Corazón de Jesús. (Cela, 1993 p. 327-331).
}

La Colmena. Gracias a Fraga Iribarne, entre 1962 y 1969 vive como escritor y director de revista privilegiado, con carta blanca oficial para torear la censura como nadie más, que sepamos, podía hacer en la España de Franco. Sus quejas en Papeles de Son Armadans sobre las trabas de la censura al Diccionario secreto de 1968 resultaron fútiles a la vista de lo que le ocurriría un año después con San Camilo, 1936 (CELA, 1968). Volvía a ser un escritor como los demás, pero el bagaje de esas experiencias y el no deberse al amigo ministro, le permitirían volar más alto en años sucesivos.

\section{Referencias}

ABELLÁN, Manuel L. Censura y creación literaria en España (1939-1976). Barcelona: Península, 1980.

CELA, Camilo José. Nota manuscrita de 13/09/1962. Correspondencia con Manuel Fraga Iribarne. Epistolario. Fundación Camilo José Cela. Iria Flavia, Padrón, 1962.

CELA, Camilo José. Carta a Manuel Fraga, 28/08. Correspondencia con Manuel Fraga Iribarne. Epistolario. Fundación Camilo José Cela. Iria Flavia, Padrón, 1967.

CELA, Camilo José. Alivio de luto. Papeles de Son Armadans, 151, octubre, 1968: 1.

CELA, Camilo José. Carta a Manuel Fraga, 25/07. Correspondencia con Manuel Fraga Iribarne. Epistolario. Fundación Camilo José Cela. Iria Flavia, Padrón, 1969a.

CELA, Camilo José. Visperas, festividad y octava de San Camilo, 1936, en Madrid. Madrid: Alfaguara, 1969b.

CELA, Camilo José. Memorias, entendimientos y voluntades. Barcelona: Plaza y Janés, 1993.

CELA, Camilo José, Carta a Corpus Barga. 10/10/1961. In Correspondencia con el exilio, Prólogo de Eduardo Chamorro. Nota sobre la edición de Jordi Amat. Barcelona: Destino, 2009a: 798-799.

CELA, Camilo José. Obra novelística. Digitalización de los manuscritos originales de todas sus novelas. Iria Flavia (Padrón). A Coruña: Fundación Camilo José cela, 2009b.

"DUEÑAS, Gonzalo" [Ángel Fernández Santos]. La ley de prensa de Manuel Fraga. París: Ruedo Ibérico, 1969.

EXPEDIENTE AGA Expediente de Censura no 9556-69, San Camilo, 1936. Alcalá de Henares, Madrid. Archivo General de la Administración (AGA), 1969-1970.

FERNÁNDEZ SANTANDER, Carlos. El general Franco. Un dictador en un tiempo de infamia. Barcelona: Crítica, 2005.

IGLESIAS LAGUNA, Antonio. Diez generaciones de escritores en el Ateneo de Madrid. In: AA.VV., Ateneo de Madrid. Memoria 1962-1967:31-51, [1968].

RODRÍGUEZ GONZÁLEZ, Olivia. Igrexa e ditadura franquista: carta de Fraga Iribarne á Conferencia Episcopal Española para mellorar a eficacia da aplicación da censura prevista na súa Lei de Prensa (28 de abril de 1967). In: AXEITOS, X. 
L.; SEOANE, E. G.; VILLARES. R (eds.). A patria enteira. Homenaxe a Xosé Ramón Barreiro Fernández. Santiago de Compostela: Consello da Cultura Galega/Universidade de Santiago/Real Academia Galega, 2008:543-566.

ROJAS CLAROS, Francisco. "Poder, disidencia editorial y cambio cultural en España durante los años 60". Pasado y memoria, v. 5, p. 59-80, 2006. Disponible en: $<$ http://www.represura. es/represura_4_octubre_2007_articulo8.html>. Acceso en: nov. 2015
SOPENA, Mireia. Con vigilante espíritu crítico. Els censors en les traduccions assagístiques d'Edicions 62. Quaderns. Revista de Traducció, v. 20, p. 147-161, 2013.

VILLANUEVA, Darío. Estructura y tiempo reducido en la novela. Barcelona: Anthropos, 1994.

Recebido: 07/01/2016

Aprovado: $15 / 01 / 2016$

Contato: olivia@udc.es 